\title{
Perfil socioambiental e econômico da comunidade ribeirinha de Bom Jardim, município de Barcarena, estado do Pará
}

O objetivo deste artigo foi realizar um analise socioambiental e econômica utilizando técnicas do Diagnóstico Rural Participativo (DRP) na comunidade ribeirinh de Bom Jardim, localizada no município de Barcarena no estado do Pará, através de técnicas metodológicas de Diagnostico Rural Participativo -DRP com observações in loco e entrevistas semiestruturadas. O diagnóstico revelou que $60 \%$ dos ribeirinhos entrevistados correspondem ao sexo masculino, $80 \%$ dos moradores não possuem água potável e cerca de $25 \%$ não realizam nenhum tipo de tratamento na água usada para o consumo. Problemas como a gripe, diarreia, vômito, febre, afligem a população evidenciando a carência de saneamento básico. Portanto, foi identificado o grande isolamento das comunidades em relação ao poder público, ausência de infraestrutura e falta de organização social e produtiva na área. A técnica de DRP permitiram à equipe e aos ribeirinhos reconhecerem as potencialidades e limitações do processo de análise de todo território, pensar em estratégias de extensão rural, intervenções nas comunidades, bem como planejamento de atividades voltadas ao desenvolvimento local.

Palavras-chave: Desenvolvimento; Diagnostico Rural Participativo; Ribeirinhos

\section{Social environmental and economic profile of the river community of Bom Jardim, city of Barcarena, state of Pará}

The objective of this paper was to perform a socioenvironmental and economic analysis using techniques of Participatory Rural Diagnosis (DRP) in the riverside community of Bom Jardim, located in the municipality of Barcarena in the state of Pará, through Participatory Rural Diagnostic-DRP methodological techniques. on-site observations and semi-structured interviews. The diagnosis revealed that $60 \%$ of the riverside respondents are male, $80 \%$ of the residents do not have clean water and about $25 \%$ do not perform any treatment in the water used for drinking. Problems such as influenza, diarrhea, vomiting, fever, afflict the population showing the lack of basic sanitation. Therefore, it was identified the great isolation of the communities in relation to the public power, lack of infrastructure and lack of social and productive organization in the area. The DRP technique allowed the team and the riparian to recognize the potentialities and limitations of the whole territory analysis process, to think of rural extension strategies, community interventions, as well as planning activities focused on local development.

Keywords: Development; Participatory Rural Diagnosis; Riparian.

Topic: Desenvolvimento, Sustentabilidade e Meio Ambiente

Reviewed anonymously in the process of blind peer.
Received: 04/05/2020 Approved: 02/07/2020
Mayra Piloni Maestri it

Universidade Federal Rural da Amazônia, Brasil http://lattes.cnpq.br/2687102042811310

http://orcid.org/0000-0002-8936-952X

mayrapmaestri@hotmail.com

Camila Amorim Santa Brigida (iD)

Universidade Federal do Oeste do Pará, Brasil

http://lattes.cnpq.br/7618034411950250

http://orcid.org/0000-0003-1229-7422

brigida88camila@gmail.com

Sarah Stephanie Rebelo Traian Baumann (iD Universidade Federal do Oeste do Pará, Brasil http://lattes.cnpq.br/7722661512593219

http://orcid.org/0000-0003-1916-1552

sarah.enflor@gmail.com

\author{
Lívia Karine Lima Rabelo \\ Universidade Federal do Oeste do Pará, Brasil \\ http://lattes.cnpq.br/2513116920954057 \\ http://orcid.org/0000-0002-7294-6423 \\ liviarabello16@gmail.com \\ Marina Cardoso de Aquino (iD \\ Universidade do Estado de Santa Catarina, Brasil \\ http://lattes.cnpq.br/2168843028631934 \\ http://orcid.org/0000-0002-0160-0804 \\ marinaacardosoo@gmail.com \\ Francimary da Silva Carneiro (iD \\ Universidade Federal Rural da Amazônia, Brasil \\ http://lattes.cnpq.br/8657235544233319 \\ http://orcid.org/0000-0002-1693-8779 \\ francimarycarneiro@gmail.com
}

\section{Referencing this:}

MAESTRI, M. P.; BRIGIDA, C. A. S.; BAUMANN, S. S. R. T.; RABELO, L. K. L.; AQUINO, M. C.; CARNEIRO, F. S.. Perfil socioambiental e econômico da comunidade ribeirinha de Bom Jardim, município de Barcarena, estado do Pará. Nature and Conservation, v.13, n.3, p.129-135, 2020. DOI: http://doi.org/10.6008/CBPC2318-2881.2020.003.0013 


\section{INTRODUÇÃO}

O desenvolvimento rural, na segunda metade do século $X X$, tinha como enfoque, principal, a modernização da agricultura, com a aquisição de novas tecnologias e serviços de assistência técnica voltados meramente para a transição no modo de produzir das populações, com o intuito de aumentar a produção, sem os incluir nas tomadas de decisões e muito menos avaliar se tal mudança condizia com a realidade desses produtores. Contudo, a partir da década de 1980 muitos estudiosos começaram a criticar esse tipo de desenvolvimento rural (SCHNEIDER et al., 2004; KAGEYAMA, 2004) em detrimento disso, novos métodos foram criados e políticas públicas foram reformuladas afim de que as comunidades se tornassem o sujeito ativo nas tomadas de decisões (NAVARRO, 2001).

Nesse cenário, é criado o Diagnóstico Rural Participativo-DRP que nada mais é do que um método alternativo onde cada indivíduo contribui, de maneira participativa, para o diagnóstico da realidade da comunidade e doravante buscam maneiras de auto administrar o desenvolvimento coletivo sobre as mais diversas questões ambientais, sociais, econômicas, entre outras. As metodologias participativas são de grande importância para o convívio social, pois proporcionam um potencial reflexivo, sobretudo em relação a realidade de determinada comunidade e, a partir daí, impulsiona as discussões sobre mais diversos âmbitos e esferas sociais (MATTOS et al., 2011).

Em todo o Brasil técnicas de DRP são utilizadas nos mais diversos âmbitos rurais e urbanos (SOUZA, 2009). Contudo, não há muitos estudos sobre essa técnica metodológica na região norte do país e essa carência é ainda mais acentuada quando se analisa o estado do Pará, estado que abriga diferentes tipos de comunidades tradicionais, como: povos indígenas, quilombolas, extrativistas, pescadores, ribeirinhos, dentre outros. Todos esses grupos têm distintas particularidades, no entanto a maior parte da população está desprovida de informação e no meio do descaso do Estado.

Os ribeirinhos se localizam as margens dos rios, em pequenos agrupamentos e vivem em casas de palafita. Eles dependem muito dos ciclos sazonais para realizar suas atividades de subsistência, sendo o período de vazante o qual é realizado a maior parte de suas atividades, como a agricultura, pesca, caça e extrativismo vegetal. Além disso, eles enfrentam inúmeras problemáticas, como a falta de saúde pública, alta taxa de analfabetismo e a dificuldade para ter acesso à educação são alguns exemplos de como esse grupo tem sido desassistido pelas ações públicas (SCHERER, 2004). Tudo isso somado as longas distancias entre as comunidades e as cidades acaba dificultando a busca e a conquista de seus direitos básicos. Diante do exposto, este trabalho tem como objetivo realizar um analise socioambiental e econômica utilizando técnicas do Diagnóstico Rural Participativo-DRP na comunidade ribeirinha de Bom Jardim, localizada no município de Barcarena no estado do Pará.

\section{MATERIAIS E MÉTODOS}

\section{Caracterização da área de estudo}

A pesquisa foi realizada na comunidade ribeirinha de Bom Jardim que está situada no município de 
Barcarena no estado do Pará, a duas horas e meia da capital paraense, pertence a mesorregião Metropolitana de Belém e a microrregião de Belém. A sede municipal possui coordenadas geográficas de 01 30'24"S e 48은 37 '12"W (Figura 1), possui 109,975 habitantes, sua extensão territorial é de $1.310,30 \mathrm{~km}^{2}$, sua densidade populacional é de $83,93 \mathrm{hab} / \mathrm{km}^{2}$ e seu índice de desenvolvimento Humano-IDH é de 0,662. O desenvolvimento deste estudo ocorreu no ano de 2012 durante o projeto esse rio é minha rua.

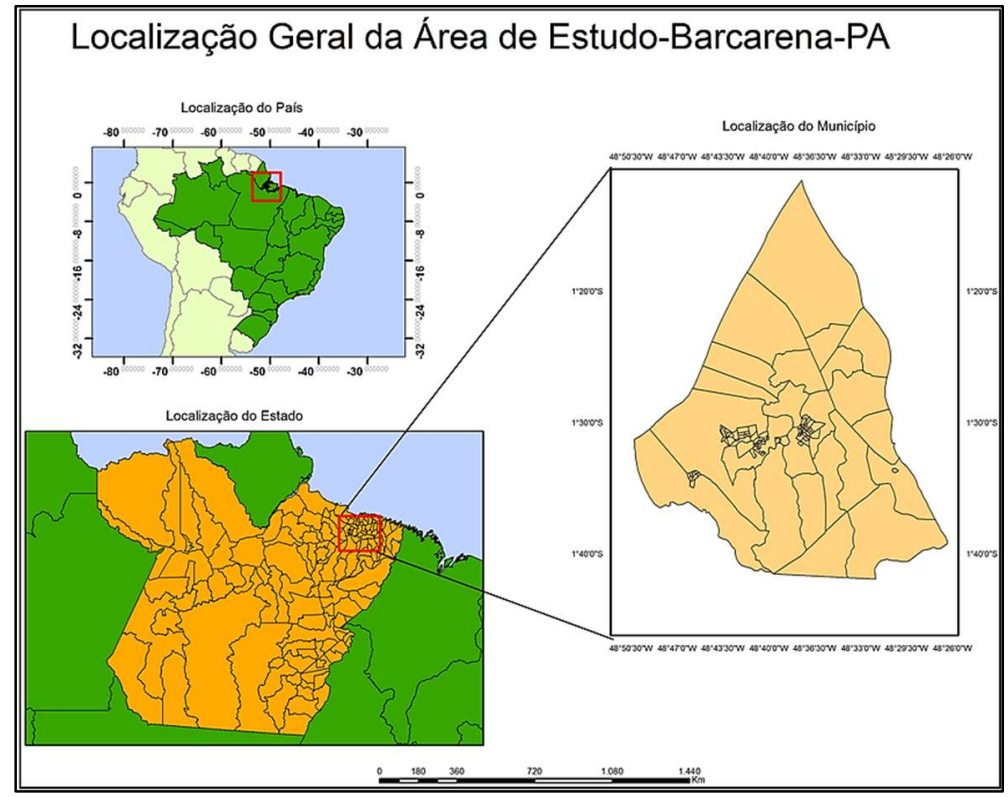

Figura 1: Mapa de localização do município de Barcarena, PA.

\section{Obtenção e análise de dados}

Para a realização do diagnóstico socioambiental e econômico foram utilizados os instrumentos metodológicos do Diagnóstico Rural Participativo (DRP) como as observações in loco, para um primeiro contato com os moradores e a busca por confiança, e posteriormente foram realizadas entrevistas semiestruturadas de forma que ribeirinhos participassem de modo interativa e com autoajuda. Para a coleta de dados e elaboração do diagnóstico foram entrevistados 24 ribeirinhos. A equipe foi composta por profissionais de diversas áreas, garantindo uma análise a partir de diferentes ângulos e multidisciplinar, evitando o predomínio de enfoques específicos.

A ficha da entrevista contou com perguntas socioeconômicas e culturais, com questões relativas ao sexo, naturalidade, estado civil, acesso aos meios de comunicação, lazer, tempo na localidade, renda, participação nas atividades sociais e comunitárias, as principais doenças que os aflige, os principais problemas da região, caracterização da propriedade e dentre outros dados relevantes necessários para a realização do diagnóstico socioambiental.

\section{RESULTADOS E DISCUSSÃO}

$\mathrm{Na}$ entrevista, $60 \%$ dos ribeirinhos entrevistados correspondem ao sexo masculino e apenas $40 \%$ ao sexo feminino. Desses, 55\% são originários do município de Barcarena, 15\% do município de Acará, 10\% do município de Curralinho, $10 \%$ da capital do estado Belém e 10\% não quiseram ou não souberam responder. 
Em relação ao estado civil, $40 \%$ são 'amigados', 35\% solteiros (as), $20 \%$ casados e $5 \%$ viúvos. Mais de $50 \%$ dos entrevistados residem na comunidade há mais de 20 anos, 15\% entre 5 e 10 anos, 10\% entre 10 e 15 anos e apenas $5 \%$ a menos de 1 ano e grande parte da população (75\%) residem em casas de madeiras (Gráfico 1). Resultados de Pereira (2006) analisando os aspectos socioeconômicos e ambientais de uma comunidade de pescadores no nordeste do Pará, concluíram que a maioria dos moradores pertence ao sexo masculino e as construções eram de madeira, dados semelhantes ao do presente estudo.

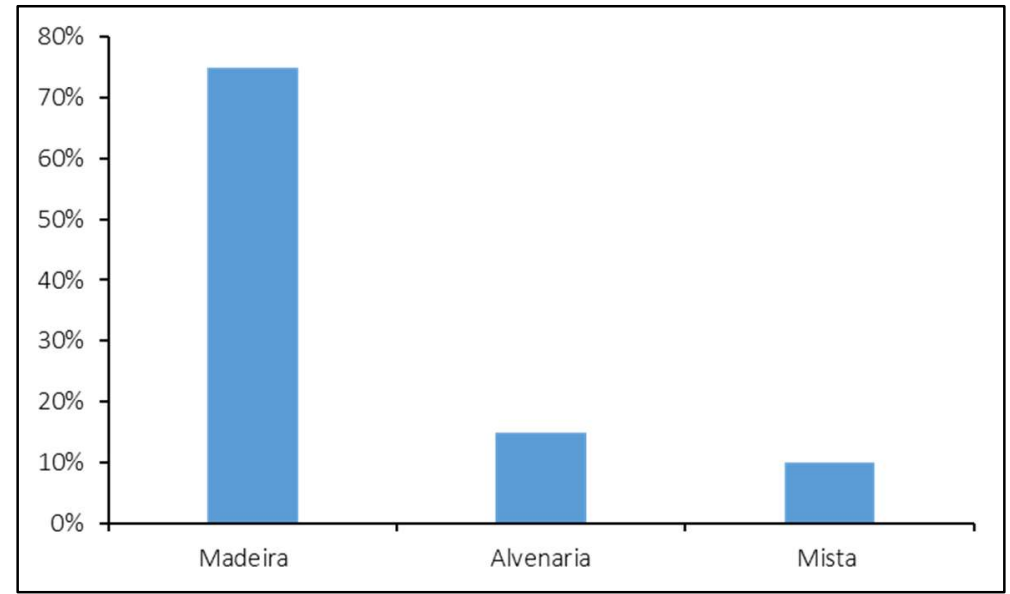

Gráfico 1: Tipos de construções dos moradores na comunidade Bom Jardim, PA.

No que diz respeito ao abastecimento de água, somente $20 \%$ dos entrevistados (Gráfico 2) possuem água potável na comunidade, pois a Prefeitura Municipal de Barcarena, por meio de um barco, realiza a entrega de água para essas famílias, no entanto, grande parte da comunidade (80\%) não possui esse abastecimento. Foi observado que, na comunidade, $75 \%$ das pessoas realizam o tratamento da água, dessas 45\% disseram acrescentar hipoclorito de sódio à água, 20\% fazem a filtração da água e $10 \%$ fervem (Gráfico 3).

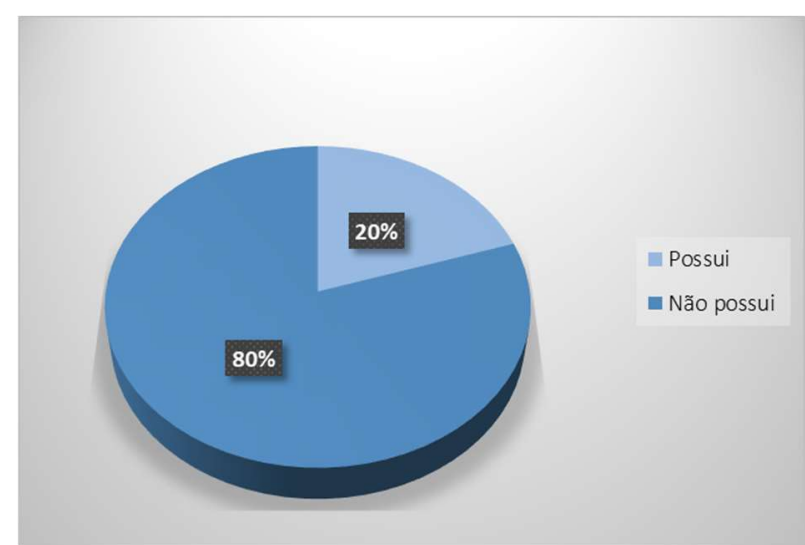

Gráfico 2: Abastecimento de água na comunidade Bom Jardim, PA.

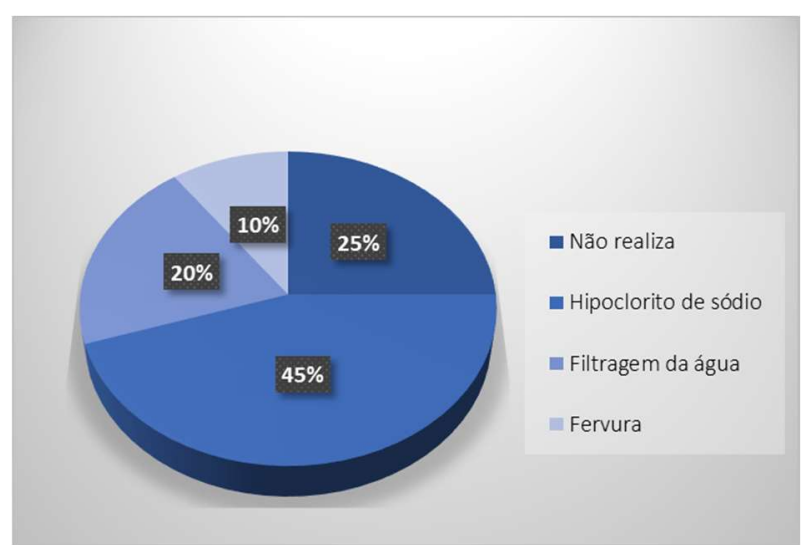

Gráfico 3: Tipos de tratamento d'água realizado pelos moradores da comunidade.

Verificou-se que mais da metade dos moradores (65\%) possuem caixa d'agua, já em relação ao armazenamento de água para o consumo foi relatado que os mais utilizados são baldes, carotes e potes, os menos utilizados são os filtros e as garrafas pets, $50 \%$ dos entrevistados disseram que na falta de água potável, bebem água do rio/igarapé, os restantes utilizam água do poço, buscam água em Belém ou 
procuram outro lugar para comprar água.

Todos os que declararam ter caixa d'água, ou outra forma de armazenamento, disseram que realizam constante limpeza em seus reservatórios, alguns mensalmente e outros quinzenalmente. Os moradores declararam que a água tem como principal utilização o consumo próprio, embora, alguns deles também batem açaí em suas casas, o que demanda água. O restante das atividades, como as de higiene pessoal, lavagem de roupas, dentre outras é usada água do igarapé. Outros entrevistados disseram que usam a água potável também para cozinhar, no entanto, alguns declararam que cozinham com água do rio.

Neste diagnóstico, percebeu-se também que a apenas $20 \%$ dos ribeirinhos possuem rede de esgoto (gráfico 4), $80 \%$ declararam não possuir, e que não realiza nenhum tratamento, despejando dejetos diretamente no rio; alguns possuem fossa e outros relataram que cavam uma trincheira e assim que ela enche tampam e abrem outra em outro local. Observou-se também que 80 \% das famílias não tem acesso a coleta publica de lixo e grande parte queimam seu lixo e somente uma minoria enterram ou reciclam. Evidenciando assim, o descaso do governo para com a dignidade humana dos habitantes da região, ferindo a Lei no. 11.445/2007 que assegura a todos o direito de possuir saneamento básico, independentemente do local onde residam. Pereira (2006) analisando os aspectos socioeconômicos e ambientais de uma comunidade de pescadores no nordeste do Pará, relataram que é agravante os problemas relacionados com a falta de saneamento básico e a água potável, em especial, é bastante rara de se ver na comunidade, contribuindo para os resultados encontrados no presente estudo.

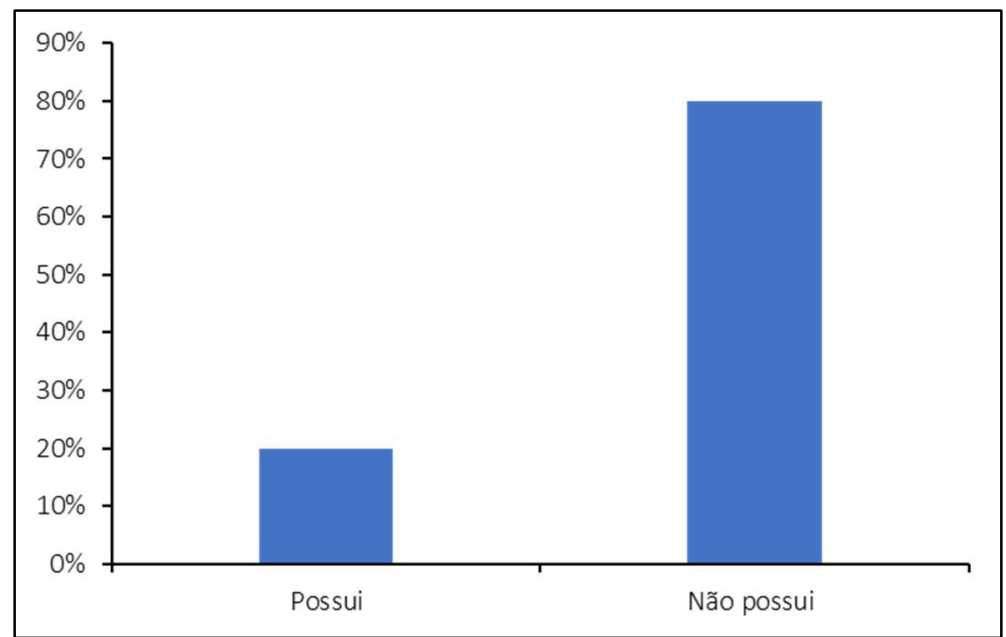

Gráfico 4: Perspectiva de moradores que tem acesso ou não à rede de esgoto.

De acordo com os moradores, as doenças mais frequentes em crianças são gripe, diarreia, vômito, febre e verme; as menos frequentes foram alergia, tosse, dores no corpo e hepatite. Para os adultos a gripe, dor no corpo, enxaqueca relacionada com o procedimento de coleta do açaí, devido as quedas das palmeiras. Em idosos a hipertensão, gripe, reumatismo, diabetes, diarreia, problemas de visão e dores no corpo. Provavelmente, boa parte das doenças relatadas são consequências da carência de serviços de água potável, coleta e de tratamento de esgoto e de lixo. Resultados obtidos neste estudo corroboraram com os encontrados por Oliveira et al. (2012) caracterizando o perfil socioambiental e a captação de água da chuva em catolé de casinhas, $\mathrm{PE}$, que o consumo de água sem tratamento adequado é responsável pela transmissão 
de inúmeras doenças.

A principal fonte de renda dos moradores é a comercialização de produtos, como o açaí, cacau, cupuaçu, pupunha, entre outros. Uma minoria vive do comercio, carpintaria e pensão. Sendo o açaí, o cacau, o cupuaçu e o peixe a base da alimentação da maioria dos ribeirinhos. De acordo com os entrevistados, $70 \%$ dos mesmos tem renda menor ou igual a dois salários mínimos, contudo está renda não é fixa, uma vez que ela varia de acordo com a safra do açaí. Os valores estabelecidos são os valores médios ocasionados no decorrer do ano, em contrapartida, durante a safra do açaí, a renda de uma família chega até 8 salários mínimos e cerca de $60 \%$ das famílias são compostas de três a quatro pessoas. Trabalhando com características socioeconômicas no Pantanal mato-grossense, alguns autores constataram que a maioria dos ribeirinhos entrevistados possuíam uma composição familiar de duas a quatro integrantes, sobrevivendo apenas com uma renda mensal de um salário mínimo, chegando bem próximo a realidade do estudo em questão.

Em relação ao controle de custos de receitas, $60 \%$ relataram que realizam o procedimento por meio de anotações em cadernos. Observou-se que a economia das famílias pode ser realizada de duas maneiras, por meio de uma conta poupança em uma instituição bancaria (35\%) ou investem todo o lucro no seu próprio terreno (65\%), e dentre as principais despesas que a comunidade possui é com a alimentação, combustível, transporte, vestuário, medicamentos, o terreno e outros.

A principal renda da comunidade é a comercialização do açaí, sendo a coleta do cacho realizada 100\% manualmente e as principais problemáticas citadas pelos produtores foram: a elevada incidência de chuva, que deixa a palmeira do o açaí escorregadio prejudicando a subida do coletor, plantas muito altas, falta de mão-de-obra e dores nas costas devido ao árduo trabalho realizado. Além disso, $40 \%$ deles relataram a incidência de pragas/doenças nos açaizeiros. Com relação aos resíduos gerados como cachos secos e semente secas ou verdes, apenas $80 \%$ dos entrevistados disseram que usam o resíduo como adubo, os restantes usam as sementes para fazer o replantio do açaí ou deixam os resíduos no local da colheita.

No que diz respeito à opinião dos entrevistados em relação as atividades sociais e comunitárias $25 \%$ alegaram não se envolver. Dos que declararam participar (75\%) citaram a associação dos moradores, a cooperativa de extração de açaí e a igreja, como forma de atuação comunitária. Além disso, todos os entrevistados acreditavam que a organização das pessoas da comunidade pode contribuir para a melhorar a qualidade de vida na localidade. Quando questionados o que poderia ser feito para essa melhoria, a maioria disse que a união dos moradores é o principal. Também foi falado sobre a conscientização das pessoas, melhoria da qualidade de vida, melhoria da renda, mais saúde e educação, assistência técnica aos produtores rurais e preservação ambiental.

\section{CONCLUSÕES}

Foi identificado o grande isolamento das comunidades em relação ao poder público, ausência de infraestrutura e falta de organização social e produtiva na área. O Diagnóstico Rural Participativo possibilitou a equipe e os ribeirinhos a se conscientizarem sobre as potencialidades e dificuldades do processo de análise 
de todo território, a pensar em estratégias de extensão rural, intervenções nas comunidades, bem como planejamento de atividades voltadas ao desenvolvimento local.

Desta maneira, os participantes observaram a importância de fortalecer a associação de moradores para buscarem alguns direitos básicos a sadia qualidade de vida das presentes e futuras gerações. E com isso, através de parcerias, garantir assistência técnica perante a EMATER e a CEPLAC, melhoria na infraestrutura, saneamento básico, coleta de lixo, agentes de saúde, dentre outros atores.

\section{REFERÊNCIAS}

BRASIL. Lei n. 11.445, de 05 de janeiro de 2007. Estabelece diretrizes nacionais para o saneamento básico. Brasília: DOU, 2007.

KAGEYAMA, A.. Desenvolvimento rural: conceito e medida. Cadernos de Ciência \& Tecnologia, v.21, n.3, p.379408, 2004.

MATTOS, C. A. C.; SILVEIRA PINTO, W.; CARDOSO, A. G.; SILVA, R. L.; BRIENZA JUNIOR, S.. Estratégias de planejamento a partir do diagnóstico rápido participativo e da análise SWOT: um estudo na comunidade de São Bento, Salinópolis/PA. Embrapa Amazônia Oriental, 2011.

NAVARRO, Z.. Desenvolvimento rural no Brasil: os limites do passado e os caminhos do futuro. Estudos avançados, v.15, n.43, p.83-100, 2011.

OLIVEIRA, G. C. S.; NÓBREGA, R. S.; ALMEIDA, H. A.. Perfil socioambiental e estimativa do potencial para a captação de água da chuva em Catolé de Casinhas, PE. Revista de Geografia, Recife, v.29, n.1, p.75-90, 2012.

PEREIRA, L. C. C.. Dinâmica socioambiental na Vila dos Pescadores (Amazônia Oriental, Pará,

Brasil). Desenvolvimento e Meio Ambiente, v.13, 2006.

SCHERER, E.. Mosaico terra-água: a vulnerabilidade social ribeirinha na Amazônia, Brasil. In: CONGRESSO LUSO-AFROBRASILEIRO DE CIÊNCIAS SOCIAIS, 8. Anais. Coimbra, 2004. p.16-18.

SCHNEIDER, S.. A abordagem territorial do desenvolvimento rural e suas articulações externas. Sociologias, v.6, n.11, 2004.

SOUZA, M. M. O.. A utilização de metodologias de diagnóstico e planejamento participativo em assentamentos rurais: o diagnóstico rural/rápido participativo (DRP). Em Extensão, v.8, n.1, 2009.

A CBPC - Companhia Brasileira de Produção Científica (CNPJ: 11.221.422/0001-03) detém os direitos materiais desta publicação. Os direitos referem-se à publicação do trabalho em qualquer parte do mundo, incluindo os direitos às renovações, expansões e disseminações da contribuição, bem como outros direitos subsidiários. Todos os trabalhos publicados eletronicamente poderão posteriormente ser publicados em coletâneas impressas sob coordenação da Sustenere Publishing, da Companhia Brasileira de Produção Científica e seus parceiros autorizados. Os (as) autores (as) preservam os direitos autorais, mas não têm permissão para a publicação da contribuição em outro meio, impresso ou digital, em português ou em tradução. 